\title{
Video observation as a tool to analyze and modify an electronics laboratory
}

\author{
Pieter Coppens" \\ KU Leuven, Faculty of Engineering Technology, 3000 Leuven, Belgium \\ and Leuven Engineering and Science Education Center (LESEC), 3000 Leuven, Belgium \\ Johan Van den Bossche \\ KU Leuven, Faculty of Engineering Technology, campus Ghent, 9000 Ghent, Belgium \\ and Leuven Engineering and Science Education Center (LESEC), 3000 Leuven, Belgium \\ Mieke De Cock \\ KU Leuven, Department of Physics and Astronomy, 3000 Leuven, Belgium \\ and Leuven Engineering and Science Education Center (LESEC), 3000 Leuven, Belgium
}

(Received 8 February 2016; published 2 August 2016)

\begin{abstract}
Laboratories are an important part of science and engineering education, especially in the field of electronics. Yet very little research into the benefits of such labs to student learning exists. In particular, it is not well known what students do and, even more importantly, think during electronics laboratories. Therefore, we conducted a study based on video observation of second year students at 3 university campuses in Belgium during a traditional lab on first order $R C$ filters. In this laboratory, students spent the majority of their time performing measurements, while very little time was spent processing or discussing the results. This in turn resulted in hardly any time spent talking about content knowledge. Based on those observations, a new laboratory was designed that includes a preparation with a virtual oscilloscope, a black box approach during the lab session itself, and a form of quick reporting at the end of the lab. This adjusted laboratory was evaluated using the same methodology and was more successful in the sense that the students spent less time gathering measurements and more time processing and analyzing them, resulting in more content-based discussion.
\end{abstract}

DOI: 10.1103/PhysRevPhysEducRes.12.020121

\section{INTRODUCTION}

Laboratories play an important role in science and engineering education. At the engineering technology faculty of our university $10 \%$ of the face-to-face time between teachers and students is during laboratory sessions (seen over the entire curriculum). In electronics subjects, the fraction of time spent in labs is even over $30 \%$. The aim of those labs is usually to teach conceptual knowledge, in addition to the working of important devices [1]. To verify to what extent students learn concepts in laboratories, we investigated the lab on first order $R C$ filters, one of the first labs in electronics courses. The study presented in this article is part of a bigger research project in which we study how engineering students learn concepts in an electronics laboratory about first order $R C$ filters. One of the methods often used in literature to measure the resulting outcome of the lab is a pretest

\footnotetext{
*Corresponding author. pieter.coppens@kuleuven.be

Published by the American Physical Society under the terms of the Creative Commons Attribution 3.0 License. Further distribution of this work must maintain attribution to the author $(s)$ and the published article's title, journal citation, and DOI.
}

post-test design [2,3], which we also adopted. Additionally, we conducted several interviews with students to probe both their understanding of the topic (first-order $R C$ filters) [4], as well as their ideas about the laboratory sessions themselves. However, the aim of this study is to gain insight into the students' behavior during the laboratory itself. Therefore, the focus of the present study is mainly the students' activities while attending a laboratory session. In order to gain insight into those, we videotaped several student pairs during the lab and analyzed the video tapes afterward by categorizing student behavior. Using video tapes of the laboratory sessions to analyze student behavior has several advantages. First of all, by observing the students in a "natural" environment, the analysis is based on their actual behavior rather than reported behavior from, e.g., interviews or surveys. Second, using a video (and audio) recording rather than a live observation protocol, for instance, allows reviewing these raw data often to ensure the analysis is done properly. As an added benefit, these raw data can be analyzed in multiple ways. Finally, by assigning student behavior to different categories, it is possible to analyze many recordings in a consistent way, without the need for a detailed transcript and lengthy discussions of the data. The aim of this analysis is to answer the following questions: 
- What activities do students perform during lab sessions? (e.g., reading, discussing, measuring, etc.)

- What are students talking about during lab sessions? (e.g., content knowledge, technical problems, private life, etc.)

- How much time is spent on the different activities and topics of conversation?

The reason for the second question in particular is that "talking about [concept knowledge] during labwork is assumed to be an important indicator for effective learning" [5], based on social constructivist ideas and, in particular, Vygotsky's emphasis on speech during active learning as an important condition for this learning to occur [6].

The paper is organized as follows. It starts with a short literature overview in Sec. II. A detailed description of the laboratory as well as the video analysis is in Sec. III. Based on this analysis (Sec. IV), the original lab was subsequently redesigned and the modifications were analyzed using the same methodology (Sec. V), after which the reformed lab was adapted and analyzed again (Sec. VI).

\section{LITERATURE OVERVIEW}

\section{A. Theory about learning}

When developing a new laboratory session, we took two important factors into account. The first is that according to constructivist learning theory, learning is an active process, where a learner interacts with the subject matter to construct a mental model [7]. A new situation either can be incorporated in an existing mental model or can cause the mental model to be adjusted. Earlier studies have shown that the latter is harder, especially when a preexisting mental model of the situation contradicts the actual events [8-10]. A specific example of such a problem is the existence of confirmation bias [11]. This means that the results of an experiment are often interpreted in favor of a desired or expected outcome.

A second factor is the cognitive capacity of the human brain. While our long-term memory has a virtually infinite capacity, it is only possible to keep a limited number of pieces of information in working memory ("in mind") at the same time. When there exists a relation between those pieces of information, the load on the active memory (cognitive load) is increased, as every link is also a piece of information. However, by practice and familiarity with the topic, a set of interconnected ideas can be abstracted to a single entity, a so-called "schema," taking only one "slot" in the active memory [12]. When designing any learning environment, it is important to be aware of the limits of our working memory. An essential aspect is to reduce any cognitive load not related to the subject matter (extraneous load) as much as possible. On the other hand, it can be beneficial to increase the cognitive load in certain situations to focus the learner on a specific aspect of the subject (germane load). An example of such an approach, that also helps with schema construction, is so-called scaffolding: initially, a student is asked to complete a task where all but the final step is provided. In subsequent iterations, more steps are removed until the student is eventually able to solve the entire task without help.

A laboratory is an environment that naturally puts a rather heavy load on students' minds. There are various pieces of equipment, often unfamiliar to the student, with a lot of screens and buttons. Next, it is often hard to gather good measurements and certainly to interpret them in the context of the new physics law, chemical procedure or engineering design that is the learning object of the laboratory. In order to stimulate student learning as much as possible, it is important to remove as many distractions as possible and focus the students' attention on the learning object, in casu $R C$ filters.

\section{B. Research about learning in labs}

Despite the importance and cost of laboratory instruction in engineering education, relatively little attention has been paid to it in literature. However, there has been some work in the area of laboratory instruction in science education. One of the aspects that has been looked at are the goals of laboratory instruction. These are often unclear or vague and students are not always aware of their teachers' intentions with the lab [13-17]. Some goals are hardly different from the goals of the course in general, making one wonder about the specific role of laboratory instruction [18]. Previous research also pointed out that what teachers intend to teach in science laboratories is not necessarily what students learn during them [19].

In engineering education the focus of labs is mostly on integrating theory and practice [20,21]. However, a lack of coherent learning objectives for labs has limited the effectiveness of laboratory instruction and has hampered meaningful research [14].

In the European Labwork in Science Education (LSE) project, the role of labs in science education and its effectiveness were studied [5]. This effectiveness is of course related to the learning objectives of the lab work. In this context, two types of effectiveness are distinguished, so-called "effectiveness 1 and 2" [22]. The first refers to how well the goals set for the lab by the teacher relate to what students do during the lab session itself. Effectiveness 2 , on the other hand, is related to what influence student activities during the laboratory have on eventual student learning outcome seen over a longer period of time. Video analysis is a tool often employed to evaluate the effectiveness 1 , in other words, to look at what goes on in a (science) laboratory. Much of this research investigates the social interaction among students or between students and their teachers [23,24], as is often done in pedagogical research [25]. Some of this research is done by researchers' detailed discussion of shorter episodes of the recordings [26,27], 
but many studies use a categorization scheme to analyze student behavior [5,28,29].

The outcome of this type of research is often an identification of problems with the effectiveness of lab work. These include too much "cookbooklike" instruction, where students follow a set of predetermined steps specified in a lab guide. The students typically reflect very little on the setup or the data, believing they have to follow the instructions to get the right answer [30]. In many labs, there is no analysis or discussion of the data [5,30,31]. Niedderer et al. even call this a "missing link between theory and practice" [5]. However, this integration between theory and practice is precisely what others claim to be the aim of lab work in engineering education [20,21]. What does happen in many laboratories is gathering data, which is not an activity that leads to a lot of talking about content knowledge [5]. While many do offer suggestions for improvement of laboratories, these suggestions are often vague or generic (e.g., to make sure the assessment is consistent with teachers' goals [30] or to use more innovative approaches [20]), while the more specific suggestions are not executed or studied in practice (e.g., to include calculations or rough data analysis in the measurement process [5]).

\section{CONTEXT AND METHODOLOGY}

This section contains a description both of the setting in which the study was performed as well as of the methodology used to analyze the labs. Section III A gives a short introduction to the topic of the laboratories, first order $R C$ filters. Section III B describes the setting of the research: the participants, their background, and the context of the labs. Section III C describes the actual methodology of the video analysis as well as the ways in which the data are represented.

\section{A. About $R C$ filters}

Before presenting the research and findings, a quick introduction into the topic of $R C$ filters may be of interest. The circuits are those shown in Fig. 1. In a typical introductory physics course, a dc voltage source is applied to the input terminals of the low-pass filter [Fig. (1a)]. The students then learn that the capacitor gradually charges: the voltage across the capacitor (at the output terminals) increases asymptotically to the value of the input voltage. The charging rate depends on the value of the resistor and the capacitor according to $V_{\text {out }}=V_{\text {in }}\left(1-e^{-t / R C}\right)$. When the voltage source is then switched off, the output voltage decreases exponentially again. However, when the switching is done very rapidly, the capacitor does not have enough time to charge fully before starting to discharge again. When applying an ac voltage, something similar happens: the capacitor does not have the time to fully charge and as a result, the output voltage will be lower than the input voltage. The higher the frequency of the input

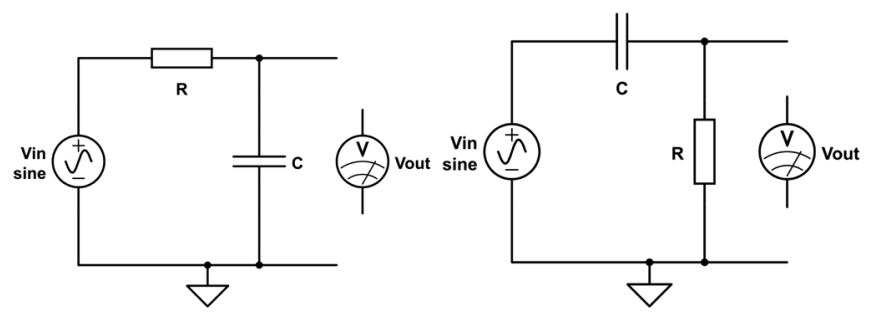

(a) Low-pass filter

(b) High-pass filter

FIG. 1. First order $R C$ filters.

signal, the less time the capacitor has to charge and the lower the output voltage will be. Something similar happens in the circuit shown in Fig. 1(b), but now a signal with a higher frequency will pass undisturbed to the output terminals while one with a lower frequency will be attenuated. In addition to the influence on the amplitude, the filters will also cause a phase shift of the output voltage with respect to the input voltage. This phase shift will be negative (lagging output) for the LPF and positive (leading output) for the HPF. For both the high- and low-pass filters, the "border" between what is considered a high and low frequency is the so-called cutoff frequency $f_{c}$. This frequency depends on the value of the resistor and capacitor: $f_{c}=1 / 2 \pi R C$ for both LPF and HPF.

Another concept that the students encounter during the laboratory sessions are Bode plots. These plots have a logarithmic $x$ axis on which the frequency of the input signal is indicated. The $y$ axis shows the voltage gain (the fraction of the output amplitude over the input amplitude), most commonly expressed in decibel $(\mathrm{dB})$. A second plot shows the phase shift of the output signal with respect to the input signal in degrees, again as a function of (logarithmic) frequency. On such a plot, one can see that the gain at the cutoff frequency is $-3 \mathrm{~dB}$, while the phase shift is $45^{\circ}$ (lagging for LPF and leading for HPF). An example is shown in Fig. 2. This type of plot is widely used in electronics to design circuits of which the frequency behavior is important, such as in filtering for audio applications, noise removal in medical signals, or radio telecommunication.

\section{B. Participants and educational context}

The study was performed at three different campuses of the faculty of engineering technology at our university. The focus was on an introductory electronics course, scheduled in the second year of the bachelor curriculum. At campuses 1 and 2, the students had chosen electronics or electromechanics as their field of study while at campus 3 the students had not chosen a specialization yet. Although details of the curricula at the campuses differ, at all three campuses this introductory electronics course included several lab sessions in addition to traditional lectures. While around 100 students were typically enrolled in a course, the lab sessions took place in smaller groups of 

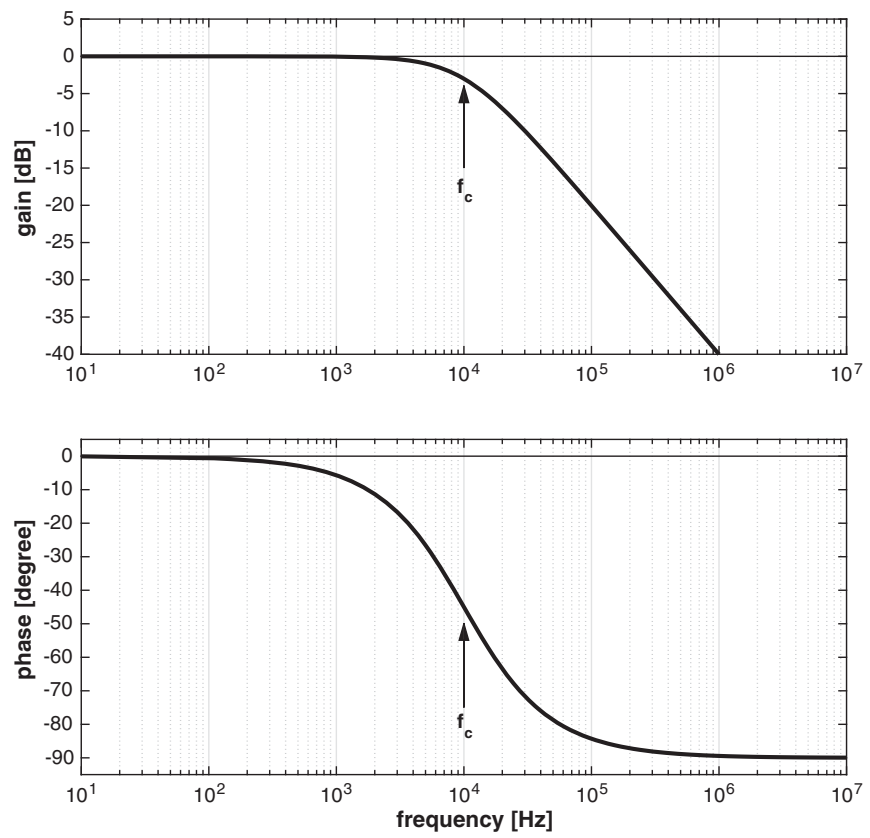

FIG. 2. Example of the Bode plot of a low-pass filter. One can see that at the cutoff frequency (here $10 \mathrm{kHz}$ ), the gain is $-3 \mathrm{~dB}$ and the phase shift is $-45^{\circ}$. It is also clear that the phase shift will be limited to $-90^{\circ}$.

under 20 students working in pairs under the supervision of one teaching assistant (TA). One of the first of those sessions was on first order $R C$ filters.

The content of the sessions was very similar at all campuses and is described in more detail in Sec. IVA, while some circumstantial factors are outlined below and in Table I. First of all, the duration of the labs was different at the three different campuses. Second, the students at campus 1 and 2 had to write a (graded) report, which was available to us. The students at campus 3 did not write reports but instead had a lab examination at the end of the semester. Finally, the students at campuses 1 and 2 had to make a computer simulation of their circuit and compare their measurement data with their simulation. The students worked in pairs during the lab and also wrote the reports together. All labs had a lab guide with instructions on the measurement procedures, the equipment and underlying theory. This lab guide also contained a list of goals for the labs, which were the same across all three campuses: to learn how to work with lab equipment (oscilloscope and function generator), to learn to construct and use a Bode plot, and to gain insight in first order $R C$ filters. These goals are explicitly stated in each of the lab guides.

In autumn 2012 and spring 2013, the original labs were observed at all campuses. In autumn 2013, 6 additional labs were observed in their original version at campus 3 . Section IV describes the findings of those sessions. In spring 2014, pilot versions of the reformed labs were tried out at campuses 1 and 2, described and analyzed in Sec. V. In autumn 2014 and spring 2015, a final version of the reformed lab was administered at campuses 1 and 3 (campus 2 chose not to participate anymore). This version is described and analyzed in Sec. VI. Table I shows an overview of the student pairs filmed and the settings, listed by campus. At campus 1 and 2, a conceptual test was administered at the beginning of the lab, taking around $15 \mathrm{~min}$ out of the total lab time.

\section{Video analysis}

By videotaping students during the lab, we wanted to gain insight in student activities, as well as in their thought process. The aim is to find out what students spend their time on during the labs (manipulating equipment, performing measurements, etc.) as well as what they talk about (concepts, technical knowledge, etc.). The latter is the best indication available for what they are thinking about without interfering with the natural course of the lab session. Moreover, talking about content knowledge is also considered an indicator for learning [32]. In addition, we wanted to find relations between what students were doing and what they were saying in order to find an indication of what type of activities trigger meaningful conversation.

We therefore used a category-based analysis of the tapes based on the so-called Category Based Analysis of Videotapes from Labwork (CBAV) [5] and, to a lesser extent, on the categories used by Warren [23]. The CBAV approach was chosen because the research questions asked in those studies are similar: how much time is spent on a certain activity and which activities promote talking about content. Especially the latter was an important attribute of the CBAV as the relation between the activities and student thinking is of particular interest. Additionally, the environment of both the CBAV study and the study presented here is similar (physics laboratories). An additional benefit of

TABLE I. Overview of settings and number of student pairs filmed, organized by campus.

\begin{tabular}{lccccccc}
\hline \hline Campus & Field & Duration & Simulation? & Report? & $N$ Original & $N$ Pilot & $N$ Final \\
\hline 1 & Electronics & 2 h 00 & Yes & Yes & 2 & $4^{\text {a }}$ & 4 \\
2 & Electronics & 3 h 00 & Yes & Yes & 2 & 2 & 0 \\
3 & General & 1 h 30 & No & No & 9 & 0 & 6 \\
& & & & Total & 13 & 6 & 10 \\
\hline \hline
\end{tabular}

\footnotetext{
a 2 prepared and 2 unprepared.
} 
the approach is that encoding can be done in nearly real time, eliminating the need for lengthy discussions or transcriptions of the video material.

During every lab session, one or two pairs of students were videotaped. They were selected at random and did not know in advance they would be videotaped. The students and the TA signed an informed consent form before starting the recording. The camera was positioned in between both students, looking "over their shoulders." Sound was recorded by either a dedicated table microphone or two clip-on microphones. Neither the videotape nor informal observation in the lab room indicated any significant interference of the recording process with the normal course of the laboratory session. For the analysis, all videos were divided into $30 \mathrm{sec}$ time slots and each slot was assigned one context category and one verbalization category. The context refers to what students are doing during the time slot, while the verbalization refers to what they are talking (or reading or writing) about. This verbalized knowledge is considered an indicator for student thinking.

An overview of the context categories used is in Table II. Table III shows an overview of all the verbalization categories. A short explanation and an example of every category is in the appendix. After using the same categories as the CBAV and analyzing the results, it was found that some categories were obsolete, such as the "computer measurement" (CME) context category, which is irrelevant for our laboratory. Other aspects were hard to fit into a category and required a new category, e.g., a discussion about the exact measurement value triggered the creation of the "measurement reading" (MR) verbalization. Another such example was the "data discussion" (DD) category: the students were pointing at their measurement results and discussing them without writing, measuring or other activities. Other categories were too broad for our purpose, for example, the "3P" category (used when a third person intervened in the pair) in which there was no distinction between an intervention of the TA in the specific observed pair ["third person" (3P) in our scheme] or a general

TABLE II. Categories for contexts. These are explained in more depth in Table V in the Appendix.

\begin{tabular}{ll}
\hline \hline Code & Name \\
\hline O & Other \\
3P & Third person \\
LG & Lab guide \\
BB & Blackboard \\
WD & Write and discuss \\
MA & Manipulating apparatus \\
ME & Measurement \\
CB & Building computer model \\
CS & Computer simulation \\
MP & Measurement processing \\
DD & Data discussion \\
\hline \hline
\end{tabular}

TABLE III. Categories for verbalizations. These are explained in more depth in Table VI in the Appendix.

\begin{tabular}{ll}
\hline \hline Code & Name \\
\hline TK & Technical knowledge \\
CK & Content knowledge \\
TC & Technical and content intertwined \\
MK & Mathematical knowledge \\
GD & Geometrical description \\
CD & Content-based description \\
ED & Example-based description \\
MR & Measurement reading \\
NV & No verbalization \\
\hline \hline
\end{tabular}

address of the TA to the entire class ["blackboard" (BB)]. Moreover, we added the "no verbalization" (NV) category. This clarified whether a time slot without a verbalization category assigned to it was a mistake in the analysis or a period during which the students were not talking. A final adaptation was made in the verbalization categories regarding data discussion: we chose to distinguish between different ways in which the data were discussed: just describing a trend ["geometrical" (GD)], comparing a (set of) measurement(s) to a given example in the lab manual ["example-based" (ED)] or analyzing based on knowledge of the underlying principles ["content-based" (CD)].

After author P.C. coded the initial set of videos, an extensive code book was created with a detailed description of the categories, including examples. The others then used this code book to analyze a video each and subsequently compare their results with those of P. C. We used Cohen's $\kappa$ to verify the interrater reliability [33]. Initial coding revealed confusion between the "mathematical knowledge" verbalization and the "calculation" context category, which was resolved after clarification and renaming (to "measurement processing" context). A second issue, also noticed by Niedderer et al., is that sometimes an activity extends from the middle of one time slot to the middle of the next. This can cause a "phase shift" in the coding of two coders, one assigning the activity to the first and the other to the second time slot. Eventual Cohen's $\kappa$ for the context was 0.68 and that for the verbalization was 0.62 , indicating a "substantial" agreement between both raters [34]. To ensure a uniform coding, the analysis discussed in this paper is based on the coding of all videos by the P. C.

The categorization scheme described above can be used in various ways to analyze laboratories. The first is to look at the context and verbalization separately to verify how often a certain activity happens or a type of verbalization occurs. Second, either can be plotted on a time line to see when it occurs, as well as which one follows another in time. Finally, in order to find out what students are talking about when performing a certain activity, it is possible to make a cross table between contexts and verbalizations. For example, the latter approach can give insight into the 
activities that trigger content-based discussion, helps to determine what the TA is talking about in front of the class, or why the students call the TA for help.

\section{ANALYSIS OF ORIGINAL LAB}

\section{A. Description}

As mentioned earlier, the laboratories are part of an introductory course in electronics. The topic of first order $R C$ filters was already covered in lecture(s) prior to the laboratory. The main idea of the original lab sessions themselves was to measure the input and output voltage of a known $R C$ filter as a function of the frequency and to describe it by using a Bode plot. At the beginning of the labs, the TA gave an introduction covering the theory, the equipment, and the measurement procedures. Then, the students received a (known) resistor and capacitor, configured as a low-pass filter (LPF) or a high-pass filter (HPF). They applied a specific (ac) voltage by means of a signal generator and measured the output voltage as well as the phase shift between the input and the output signal using an oscilloscope. By varying the frequency of the input signal and performing repeated measurements, the students could then calculate the gain in decibel $(\mathrm{dB})$ for every frequency and construct a Bode plot. While they were all required to compare their measurements to their theoretical expectations, only the students at campuses 1 and 2 also did simulations of their circuit to compare their measurements with. Students were required to comment on their measurement results and indicate how they differed from the theoretical and/or simulated results and to come up with an explanation for those differences. The differences can be attributed to a variety of causes, most notably a tolerance on component value (typically $5 \%-10 \%$ ), measurement errors (it is hard to read an amplitude or phase visually on an oscilloscope screen) and input inaccuracies (the function generator's amplitude and frequency are not exact). As a result of these errors, the cutoff frequency will typically not be where it was expected and there will be a certain degree of noise on the measurements, causing (small) conflicts between, e.g., a phase shift of $45^{\circ}$ while the gain is $-2 \mathrm{~dB}$.

\section{B. Results}

Figure 3 is an overview of how often every category appeared in the original labs. The bins are the contexts in the left figures, while the colors show verbalization. The right column has the reverse: bins for verbalization and color for contexts. The results at campuses 1 and 3 were rather similar, while those at campus 2 differed and are discussed separately.

\section{Campuses 1 and 3}

At campuses 1 and 3, the labs typically started with an introduction by the TA (context $\mathrm{BB}$ ). This introduction consisted of two main parts, a theoretical one (verbalization $\mathrm{CK}$ ) and a technical one (verbalization TK). At campus 3, the theoretical part also included a purely mathematical explanation of the theory (verbalization MK). The technical part at both campuses consisted of an introduction to the lab equipment, mainly the oscilloscope and function generator. The entire introduction took around $20 \mathrm{~min}$, which corresponds to around $20 \%-25 \%$ of the total lab time. Together with shorter episodes later during the lab, the total time a TA talked to the class as a whole could rise to over $50 \%$ for some labs, especially at campus 3 .

The time the students are working in pairs starts by setting up their equipment (context MA). During this phase, they often switch to their manual (context LG) and sometimes to the TA or fellow students (context 3P) for help with technical problems (verbalization TK). After that, most of the students' time is spent conducting measurements (context ME). During the measurements, most of the verbalization is reading off values (verbalization MR), although sometimes there are comments relating different measurements to one another (verbalization GD). At campus 3, however, very little time is spent performing measurements, most of the time there is used to set up the equipment (context MA) and little time is left to gather measurements (context ME).

During the lab, hardly any measurements are processed or plotted (context MP). In turn, this leads to very little data discussion (context DD). The discussion that does happen is either graphical (verbalization GD) or a comparison with an example in the lab guide (verbalization ED). Only rarely is it related to content knowledge (verbalization CD). The students at campus 1 also did not make a computer model of their circuit (context $\mathrm{CB}$ ) and subsequently did not do any simulations (context CS) during the assigned lab time despite it being a requirement of the lab.

As a lot of time is spent manipulating equipment (context MA) or performing measurements (context ME), an obvious consequence is that most verbalization is technical knowledge (verbalization TK) or reading off measurements (verbalization MR). It also appears that a sizable part of the lab is spent discussing pure content knowledge (verbalization CK). However, closer inspection clearly indicates that this is mainly (over 90\%) done by the TA (contexts BB) or is initiated by the TA (context 3P). Very often there is no verbalization at all, most often when the students are working with their equipment (context MA). The only content knowledge the students use themselves is expressed mathematically (verbalization MK), without indication they understand it also conceptually.

\section{Campus 2}

At campus 2, the introduction is very short, since the students here already worked with an oscilloscope before and were required to prepare for the lab. The students there also started by constructing a computer model (context 


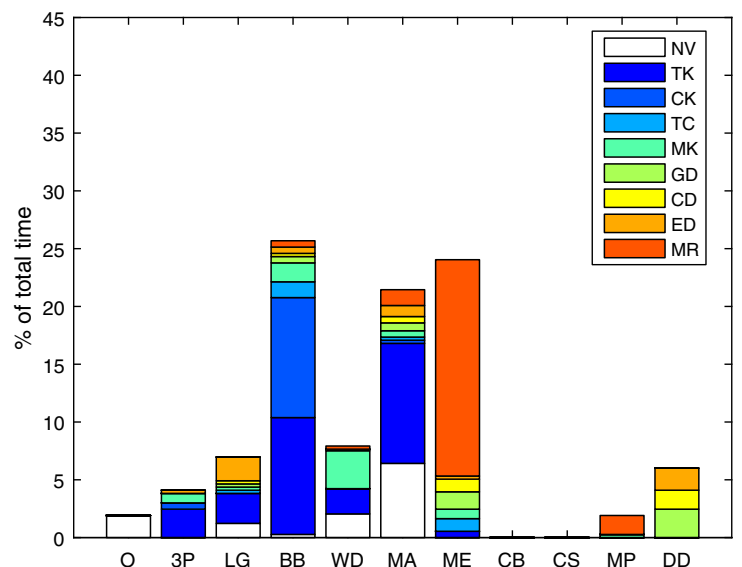

(a) Contexts for students at campus 1 with verbalization color-coded

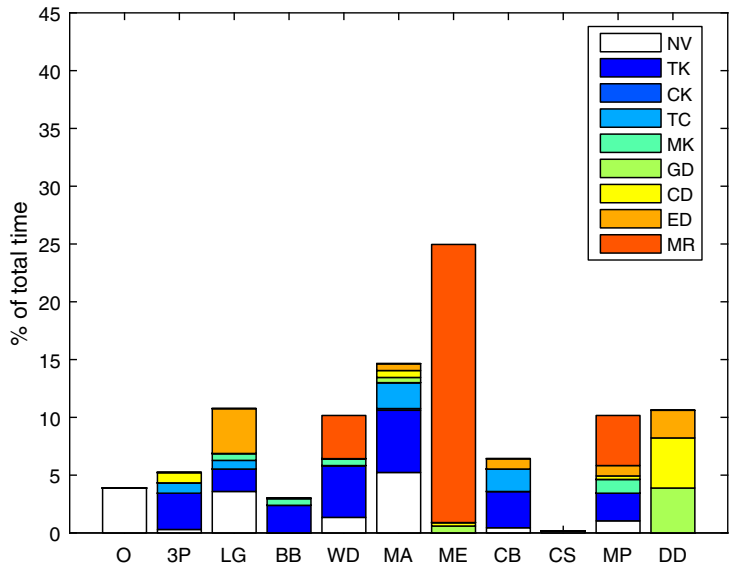

(c) Contexts for students at campus 2 with verbalization color-coded

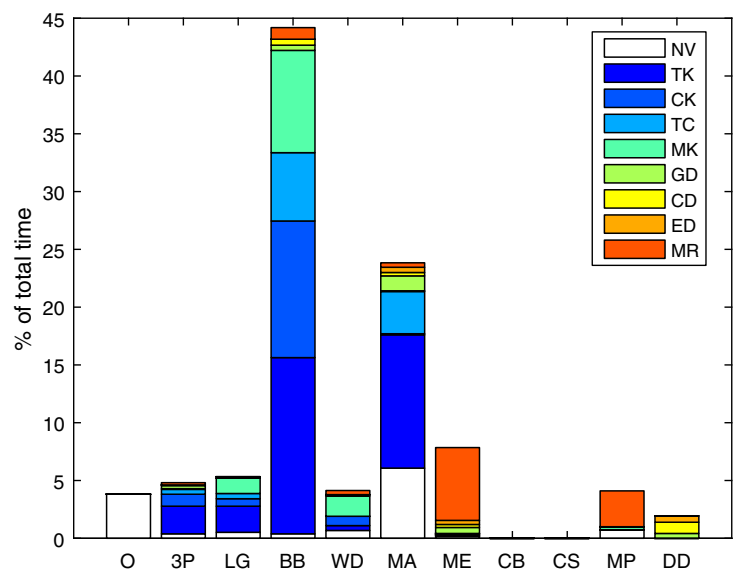

(e) Contexts for students at campus 3 with verbalization color-coded

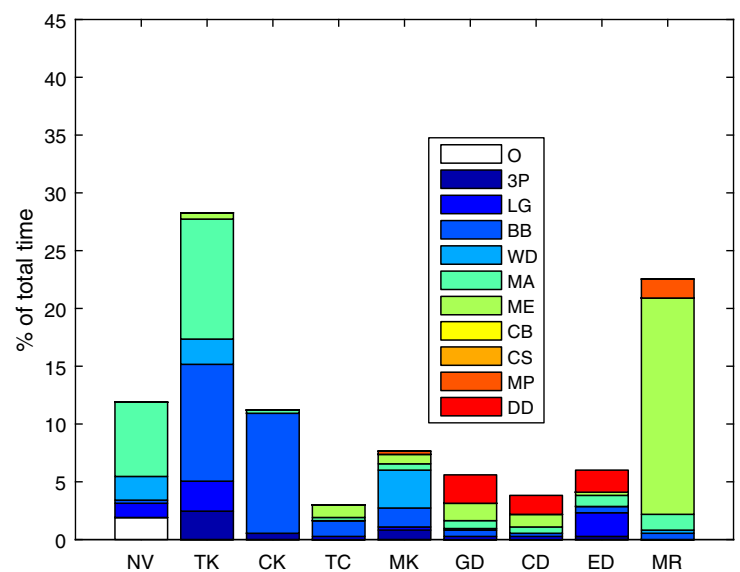

(b) Verbalizations for students at campus 1 with context color-coded

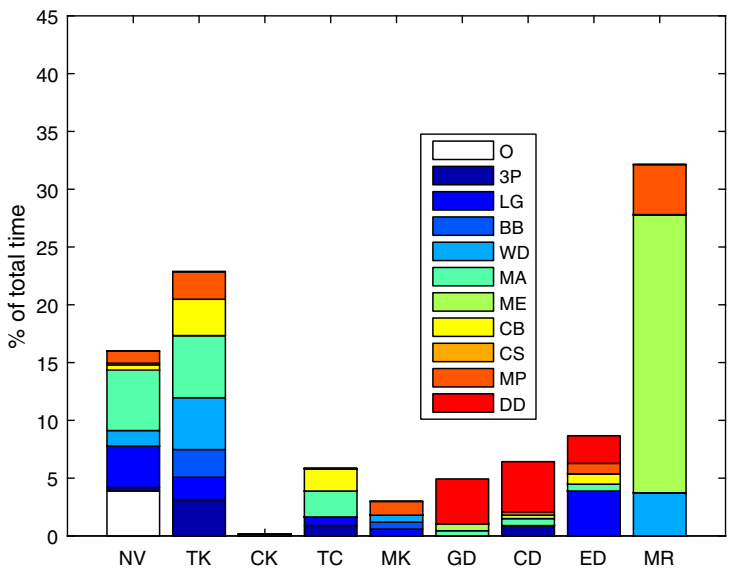

(d) Verbalizations for students at campus 2 with context color-coded

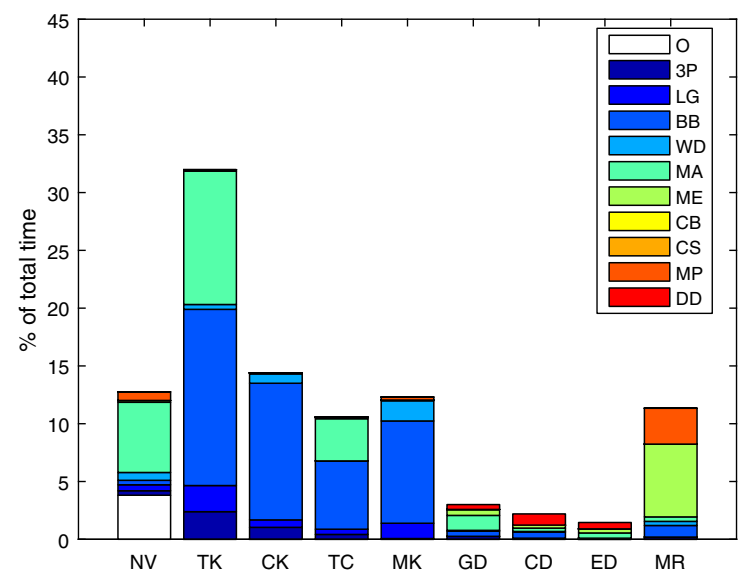

(f) Verbalizations for students at campus 2 with context color-coded

FIG. 3. Results of original labs. All percentages are the total of all pairs at the different campuses. Left are contexts in bins with verbalization marked by colors (a), (c), and (e), while right are verbalizations in bins with the contexts marked by colors (b), (d), and (f). The rows are campus 1 [(a) and (b)], 2 [(c) and (d)], and 3 [(e) and (f)], respectively. 
CB) before doing any measurements. During this model building, they often copied code from their manual (verbalization ED) and struggled to adjust it to their needs. Afterward, they performed the lab much like the students at the other campuses, starting with setting up their equipment (context MA) and then performing a long series of measurements (context ME). They spent more or less the same amount of time on setting up their equipment (context MA) as their colleagues at the other campuses (in absolute terms). During the measurements (context ME), they do not process or discuss them at all. However, they did process (context MP) and discuss (context DD) them afterward, most often from a content point of view (verbalization $\mathrm{CD}$ ) and comparing their measurements to values of their simulations (verbalization GD).

\section{Discussion}

At the beginning of the laboratories at campuses 1 and 3 , there was a long introduction by the TA, which covered both the theoretical aspects of $R C$ filters and a demonstration of the lab equipment. Afterward, most of the time at those campuses was spent measuring and dealing with lab equipment. To explain this observation discussed in Sec. IV B, we reviewed the relevant sections of the recordings in more detail.

A first observation was that many students had a lot of trouble configuring the oscilloscope correctly and struggled to read measurements, including amplitude and phase. An example is the following statement made by one of the students, 40 min into his lab session:

STUDENT1: 9 marks is one full cycle, so that is $180^{\circ}$

At campus 3, this even led to students not able to gather enough measurements to draw any conclusions from. The specific problem with oscilloscopes has also come to the attention of Bernhard [35] and was mentioned by several students during the interviews.

A second problem that emerged is that the students at all campuses rely heavily on a set of example measurements in their lab guides. Many students actually built the same circuit as in the example and copied the input frequencies, and those who built a different circuit often did not choose their input frequencies accordingly. An example are the measurements handed in by one of the students at campus 1 shown in Table IV. The students here had a filter with a cutoff frequency around $2 \mathrm{kHz}$, but did not adjust their measurement grid accordingly.

A third common problem that is illustrated by student measurements is that students often do not judge their measurements critically. An example is from two students who had a low-pass filter with a cutoff frequency of "5894.6 Hz." They measured their output signal at $5846 \mathrm{~Hz}$ and found that their phase shift was $-48^{\circ}$ while the gain was $-20.35 \mathrm{~dB}$. They did not realize it is impossible to have a phase shift of about $-45^{\circ}$ with a gain that is this different from $-3 \mathrm{~dB}$.
TABLE IV. Example set of measurements as taken by one of the pairs during the original lab at campus 1 .

\begin{tabular}{lcc}
\hline \hline $\mathrm{f}[\mathrm{Hz}]$ & $\mathrm{A}[\mathrm{dB}]$ & $\phi[\mathrm{deg}]$ \\
\hline 10 & -44 & 90 \\
100 & -28 & 86 \\
1000 & -8 & 65 \\
2000 & -3 & 48 \\
5000 & -1 & 23 \\
7000 & -1 & 21 \\
10000 & -1 & 14 \\
20000 & -1 & 7 \\
$\ldots$ & $\ldots$ & $\cdots$ \\
\hline \hline
\end{tabular}

A next aspect worth mentioning stems from the interviews, where students said that they only processed their measurements and did the simulations at home, after the lab. Only then they would discuss the measurements, sometimes realizing they did something wrong during the lab, but unable to correct their measurements without access to the lab. In other words, snot processing the measurements during the laboratory itself prohibits any reflection or discussion about them.

Finally, the evaluation of the measurements in the lab reports, if done at all, was very superficial. An example is "the measurements agree with the simulation" in their report. The latter is an indication of confirmation bias: instead of observing that their measurements are somewhat different from theory and looking for the cause, the students have the "correct" answer in mind and fail to see anything else. A clear example is a set of measurements with the following sequence of input frequencies: (...) 2, 3, 4, $5.895,6,7,8 \mathrm{kHz}(\cdots)$. It is rather strange to have a series of nicely rounded frequencies with the exception of one very precise frequency (the cutoff frequency). This corresponds strongly with the findings of Niedderer et al. [5]:

"All findings together indicate, that data analysis often is not an important part of lab work. These results would also be in line with the assumption, that students mainly aim at 'gathering data' and not at 'reflecting theoretically' which can be seen as one way 'to link theory to practise'."

It appears that similar observations can be seen here: students spend almost all their time gathering measurements, mainly because they seem to have problems using the oscilloscope.

However, we suspect that the main reason students spend little time discussing content (verbalizations CK or $\mathrm{CD}$ ) is most likely that there are many aspects of the lab in addition to the content that are new to the students. This has been observed by Niedderer et al. in a different laboratory course on electronics, where "Learning to experiment, to solve problems with the apparatus and to apply new theory was too much at one time." [3]. In this 
case, it is the first time they encounter $(R C)$ filters, which they have to measure using equipment they have never used (oscilloscope and function generator) and subsequently have to process the data in a way they never did before (Bode plot). We hypothesize that this leads to the students being overwhelmed, making it hard for them to learn about any of those aspects. In other words, many students suffer from a cognitive overload: there are too many unfamiliar aspects to the laboratory that they have to keep in mind simultaneously. At campuses 1 and 3, the students also did not review $R C$ filters before entering the lab as they were not required to prepare. This is less evident at campus 2, where the students did process and discuss their measurements. Besides having enough time for that, the students at this campus were also required to prepare for the lab by answering a series of theoretical questions about $R C$ filters. Moreover, this was not the first laboratory in which they used oscilloscopes, although they still seemed to struggle with their usage.

\section{ANALYSIS OF THE PILOT VERSION OF THE "BLACK BOX" LAB}

\section{A. Description}

One of the first problems with the original lab was that students were not prepared at all at campuses 1 and 3 . A second problem was that students were not familiar with the equipment and, consequently, spent a lot of time setting it up (context MA) and gathering measurements (context $\mathrm{ME}$ ), sometimes not even managing the latter. A final problem was that students did not process their measurements during the lab and so did not manage to discuss them in order to "link theory to practice" [5]. An exception are the students at campus 2 , who do process their measurements during the laboratory sessions.

As discussed in Sec. IV C, we hypothesize that the problems in the original laboratories were caused by overwhelming the students with too many unfamiliar things at the same time, including new equipment, processing, and actual content. The main idea of the reformed lab is to try to avoid the students being overwhelmed by separating some new aspects from the actual lab to a preparation. This way, their knowledge base at the start of the lab is expanded, lowering the cognitive load during the laboratory session itself and freeing up cognitive capacity for the main topic of the lab, namely, the $R C$ filters themselves.

To ease the students into two new aspects, namely, the use of the oscilloscope and Bode plot, they were asked to prepare for the lab by doing two exercises made available online before the lab. The first exercise used a Matlab oscilloscope simulator, which the students could use to practice both reading and configuring a virtual oscilloscope. The simulator generated two random sine waves and set the "buttons" of the oscilloscope in such a way that it

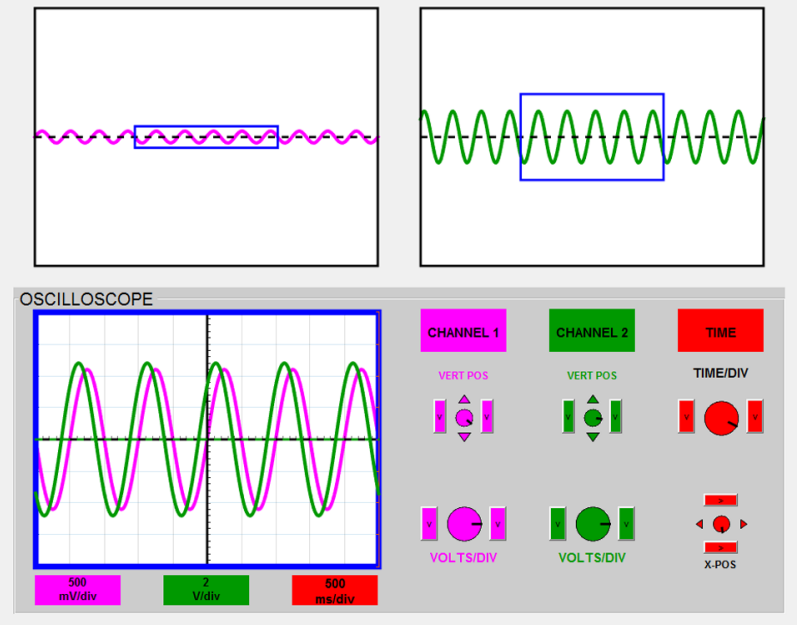

FIG. 4. Original oscilloscope simulator. The screens on top show the "total" signal, with portion shown on the oscilloscope screen in the blue rectangle.

was impossible to read the signal properly. The students then had to adjust the settings so they could measure the amplitude and frequency of both, as well as the phase shift between them. This simulator is shown in Fig. 4. The second exercise showed a set of measurements and asked the students to sketch a possible Bode plot for them. They were required to hand in the preparation at the beginning of the lab. These exercises aim to make the students more familiar with two new aspects during the lab, helping them to already create a "schema" for these aspects in advance. That way, the extraneous cognitive load is decreased, freeing (active) memory for the actual laboratory subject. Additionally, an increased proficiency with especially the oscilloscope should decrease the time spent measuring, freeing not only memory capacity, but also time to discuss the measurement results.

The lab itself was also changed. Instead of getting known components in a known configuration, all students got a "black box" like the one in Fig. 5. The box contained a resistor and capacitor from a short list of possible values in an unknown configuration (LPF or HPF). The first task of the students was to determine the content of this black box by using a function generator and oscilloscope as before, in addition to an Ohmmeter (multimeter). They were also given the list of possible component values. By using (literally) black boxes, any possible confirmation bias is eliminated. This approach also increases the germane cognitive load by forcing the students to properly process and interpret their measurement results. This idea of using black boxes in electricity laboratories has been proposed in literature before [36,37], but only rarely has the effect of using this approach been studied [38]. To our knowledge, it has not been tried for $R C$ filters.

Second, an additional resistor or capacitor with an identical value to the original component could be added 


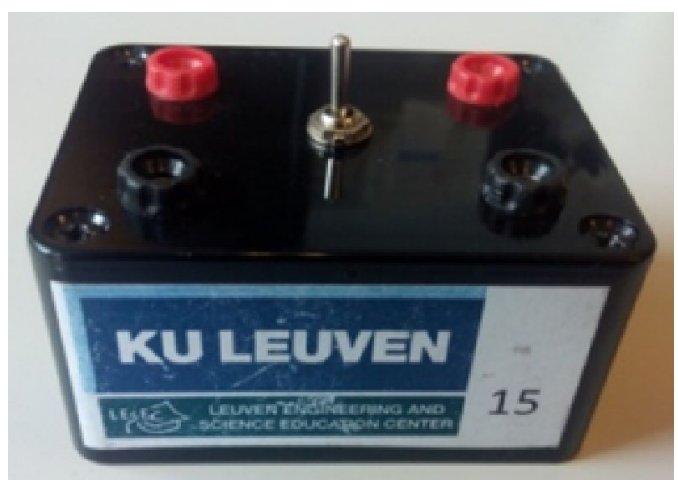

(a) 'Black box' itself

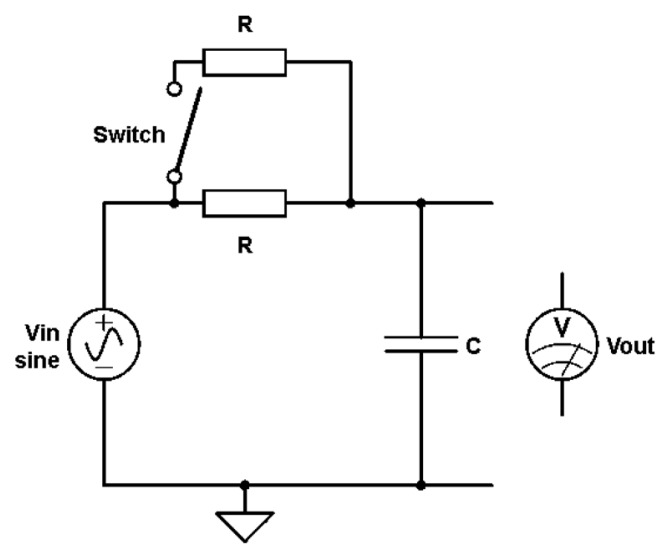

(b) Underlying circuit

FIG. 5. Black box used in the new labs. (a) The box itself: The black connectors are the ground level, while the red ones are the signal. The input is on the left, output on the right. Every box is unique and has an individual number (here 15). An example of an underlying circuit is shown in (b).

in series or parallel with the original component by means of a switch on top of the box. An example of a complete circuit is shown in Fig. 5(b). This example shows an LPF with a resistor added in parallel when the switch is thrown. This idea of adding an extra component was inspired by the so-called "variation theory" approach used by Bernhard [39]. In this approach, learners are confronted with a change in one variable while the others are kept constant. The aim is then for the learner to find out what effect this change will have. Here, the students were told the switch added either a resistor or capacitor with the same value as the original circuit, in series or parallel to the same component, but not which one exactly. They had to find out the exact configuration of the circuit with the switch themselves.

The ideal reasoning in the laboratory starts by applying a known sine wave to the input and measuring the resulting output signal. From this, one can construct a Bode plot of the filter in the black box, much like the approach used in the original labs. The measurements indicate whether the box contains an LPF or HPF, either by only looking at the phase or by looking at the amplitude as a function of the frequency. This in turn makes it clear between which two terminals on the box the resistor is situated. Using a multimeter, one can then measure the value of $R$. By taking more measurements at the appropriate frequencies, the cutoff frequency $\left(f_{c}\right)$ can be pinpointed, which in turn depends on the product of $R$ and $C$. Since the value of $R$ and $f_{c}$ are known, $C$ is found by using $f_{c}=1 / 2 \pi R C$. Knowing all component values as well as the type of filter, the entire configuration is now known. After flicking the switch, the same approach can be used. In this case, a change in resistor value makes it clear immediately what the switch does, while if the capacitor is changed, one can use the change in $f_{c}$ to determine the exact configuration.
The manual of the lab was rewritten to adjust the instructions to the black box approach used. In addition, the set of example measurements was removed and several conceptual qualitative questions were added. Examples are "what does the ac setting on an oscilloscope do" or "how would you build a bandpass filter." These questions are inspired by the questions asked to students in the "Physics by Inquiry" models developed by McDermott and Shaffer $[40,41]$. The students at both campuses were still required to make a computer simulation, as well as to hand in a report of their lab.

\section{B. Results}

As indicated in Table I, four pairs of students at campus 1 and two pairs at campus 2 were recorded while performing the pilot lab. At campus 1, two initial groups of students did not prepare for the lab. After email reminders to the other groups, the next two did prepare. This resulted in two different sets of data for this campus in the pilot version of the lab. The results of all six pairs are shown in Fig. 6.

By comparing Figs. 3(a) and 3(b) with Figs. 6(a) and 6(b), respectively, it is clear that the unprepared students behaved similarly to the students during the original labs: they spent most of their time struggling with equipment (context MA) or performing measurements (context ME). When discussing their data, however, (context DD), they did so more often from a content-based point of view (verbalization CD) than during the same context in the original laboratory. More concrete, this means that they, for instance, realize that when they measure a gain of $-3 \mathrm{~dB}$, this means their input frequency is the cutoff frequency. This was opposed to the original laboratory where one pair simply observed that the gain "kept decreasing." Again, they did not process their measurements (context MP) during the lab, nor did they do any computer simulation (context CB and CS), as is clear from 


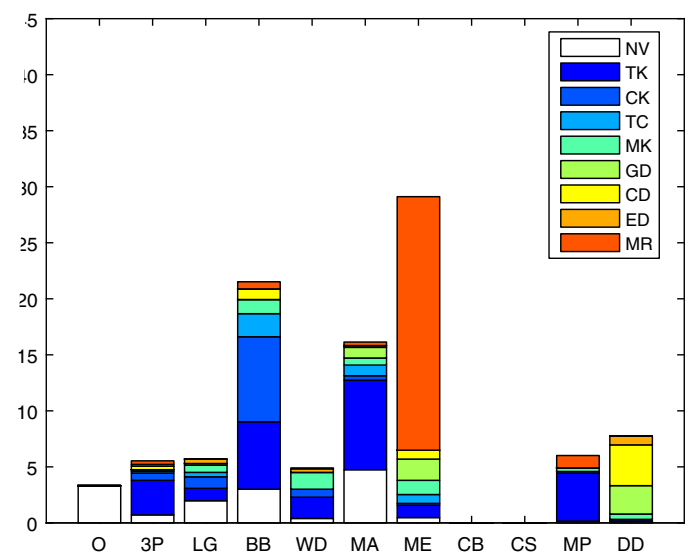

a) Contexts for unprepared students at campus 1 with verbalization color-coded

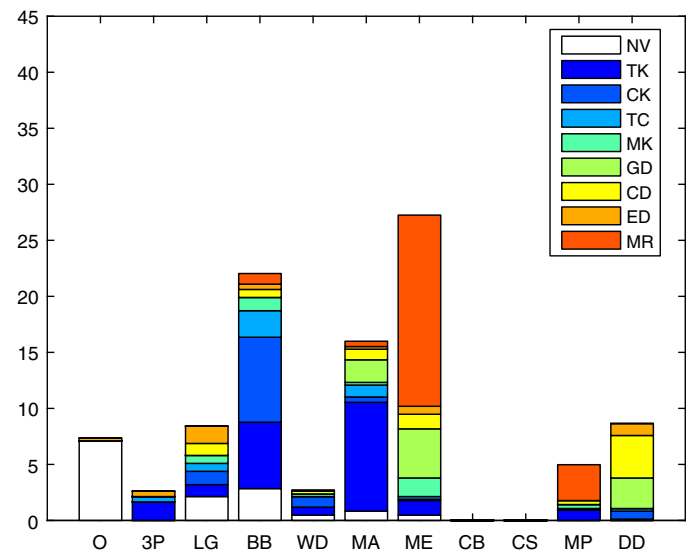

c) Contexts for prepared students at campus 1 with verbalization color-coded

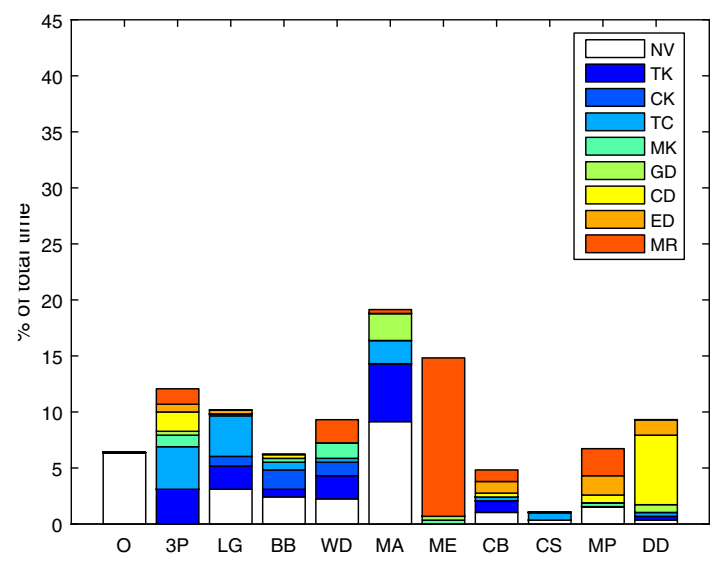

(e) Contexts for students at campus 2 with verbalization color-coded

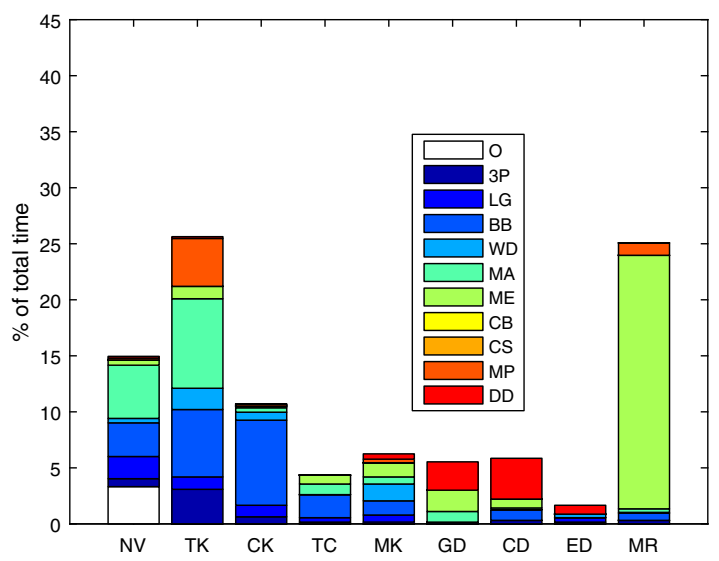

(b) Verbalizations for unprepared students at campus 1 with context color-coded

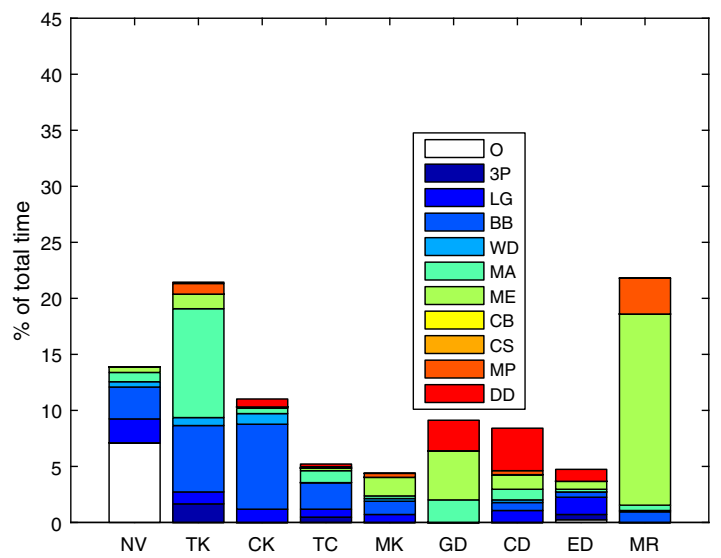

(d) Verbalizations for prepared students at campus 1 with context color-coded

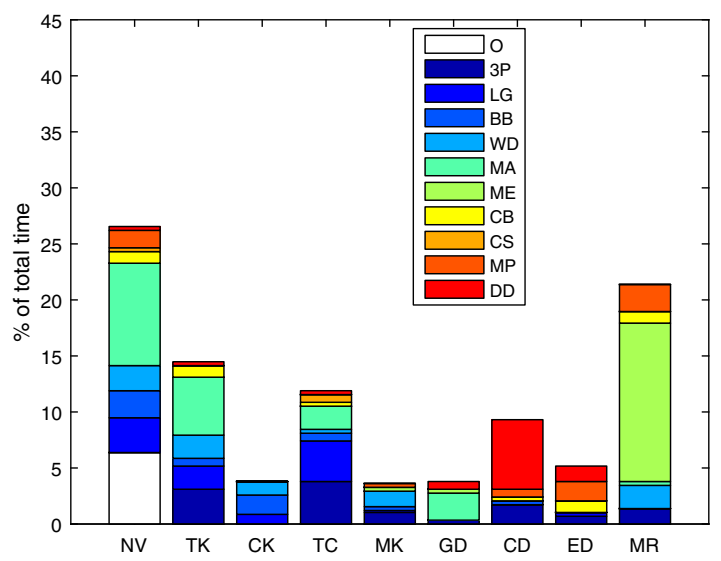

(f) Verbalizations for students at campus 2 with context color-coded

FIG. 6. Results of pilot labs. All percentages are the total of all pairs at the different campuses. Left are contexts in bins with verbalization marked by colors (a), (c), and (e), while right are verbalizations in bins with the contexts marked by colors (b), (d), (f). The first and second row are, respectively, the unprepared (a) and (b) and prepared (c) and (d) students of campus 1, while the (prepared) students of campus 2 are on the third row (e) and (f). 
Fig. 6(a). The introduction by the TA (context BB) was more or less the same as in the original labs.

The prepared students spent about as much time as their colleagues measuring (context ME), although they were more likely to comment on their measurements (verbalizations $\mathrm{CD}, \mathrm{GD}$, and $\mathrm{ED}$ ) while measuring. They also did not spend any more (or less) time processing their measurements (context MP) and did not do any simulations either (contexts CB and CS). They did spent more time reading their lab manual (context $L G$ ) instead of talking to the TA or fellow students (context 3P).

\section{Discussion}

A lot of time in the new laboratory was still used for the introduction by the TA at the beginning of the lab, shortening the time available to the students to gather and analyze their measurements. Additionally, most of the time is still spent struggling with equipment and gathering measurements. Informal discussion with the students revealed that they found it difficult to work with the simulator as it did not include any information on how to read a signal from an oscilloscope. Also, there did not seem to be much difference between prepared and unprepared students: they spent more or less the same amount of time gathering measurements and hardly any in processing them.

However, looking at the time line sheds light on the reason why even the prepared students spent so much time measuring: they managed to perform two sets of measurements in the same amount of time, essentially performing twice as many measurements. The first time with the switch in the first position, the second time with the switch in the second position. Figure 7 shows this very clearly for one of the observed pairs (it was equally clear for the other pair). The very brief measurement in between both blocks is the measurement of the resistor value. This is a clear indication the preparation helped to speed up the measurement process.

Another improvement overall was that all students thought about which measurement point to take next from a content perspective instead of using the example from the manual. This was indicated by reviewing the video data for when the students discussed data from a content-based point of view (verbalization CD) while gathering measurements (context ME). In practice, this means that the students behaved similarly to both students in the discussion below, who had a low-pass filter with a cutoff frequency between 1 and $10 \mathrm{kHz}$. They measured a phase
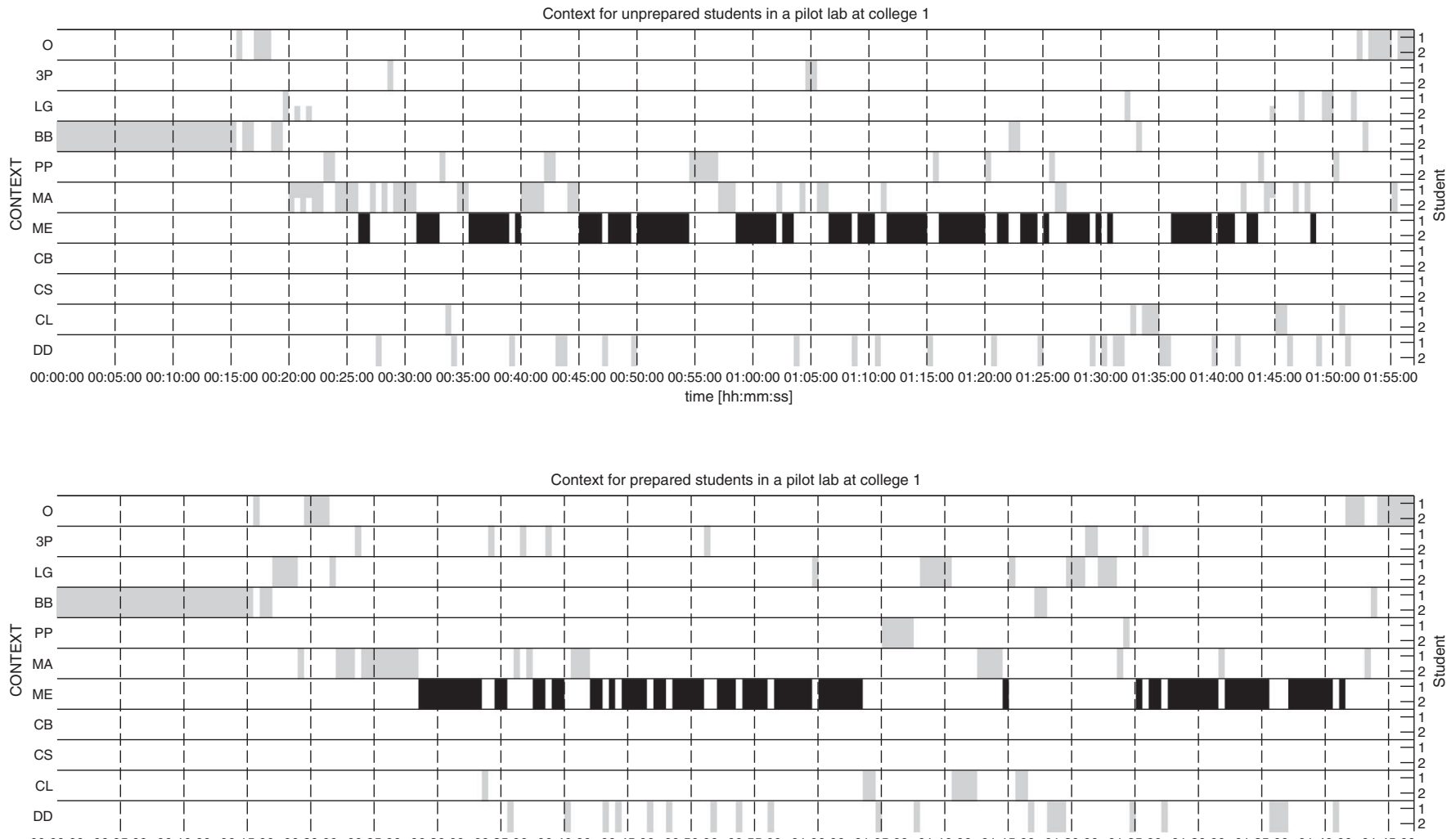

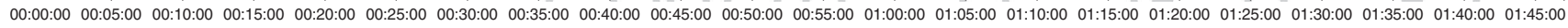

time [hh:mm:ss]

FIG. 7. Time lines for unprepared (top) and prepared (bottom) students in the pilot version of the new laboratory. Each line represents a context category and a block means that the activity represented by a context is done by the students. The highlighted line indicates the measurement context (ME). It is one more or less continuous block of measurements for the unprepared students, while there are two distinct clusters for the prepared students. 
shift of $-18^{\circ}$ at $1 \mathrm{kHz}$ and just measured a phase shift of $-68^{\circ}$ at $10 \mathrm{kHz}$ :

STUDENT1: Ah, so we're past the cutoff already.

STUDENT2: Yeah, our cutoff frequency is somewhere here [between 1 and $10 \mathrm{kHz}$.

STUDENT 1: Then we should do some more measurements in between those two.

However, the recordings also showed that most students still did not actually process and properly discuss their measurements, nor did they do any simulations. Consequently, they did not compare their measurements to the simulations or theoretical values during the laboratory sessions themselves.

\section{ANALYSIS OF THE FINAL VERSION OF THE BLACK BOX LAB}

\section{A. Description}

As indicated in Table I, a final version of the black box laboratory was introduced at campuses 1 and 3 (campus 2 withdrew from the project). Four pairs of students were recorded at campus 1 and six were recorded at campus 3 .

The preparation was kept the same as with the pilot version of the lab, although the oscilloscope simulation was altered. In the new simulation, a scaffolding approach was used by adding a "learning unit." In the learning unit, shown in Fig. 8(c), the students can practice

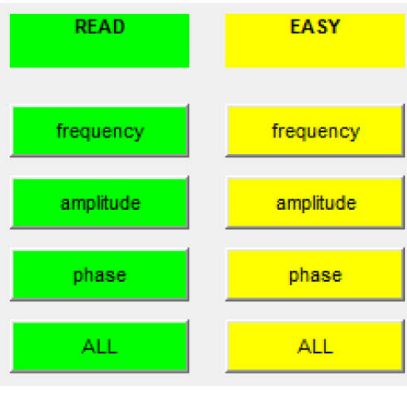

(a)

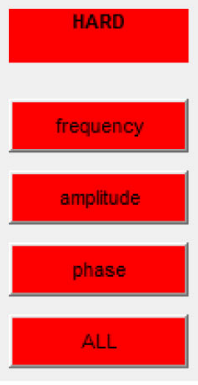

(a)
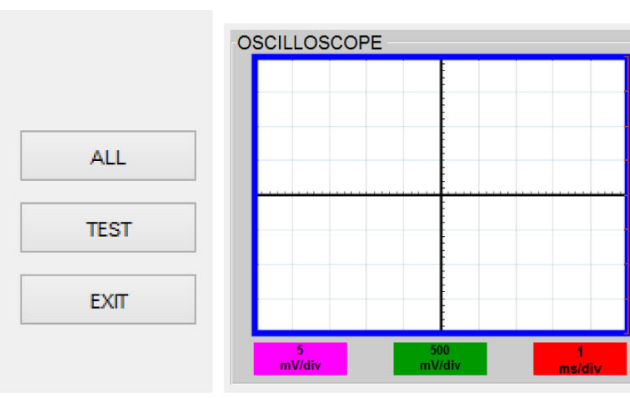

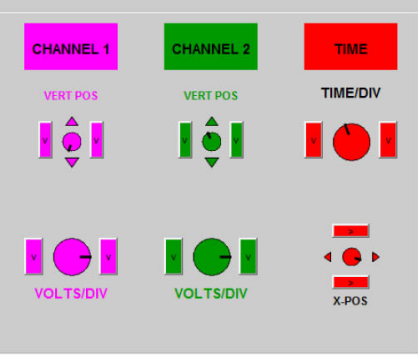

(b)

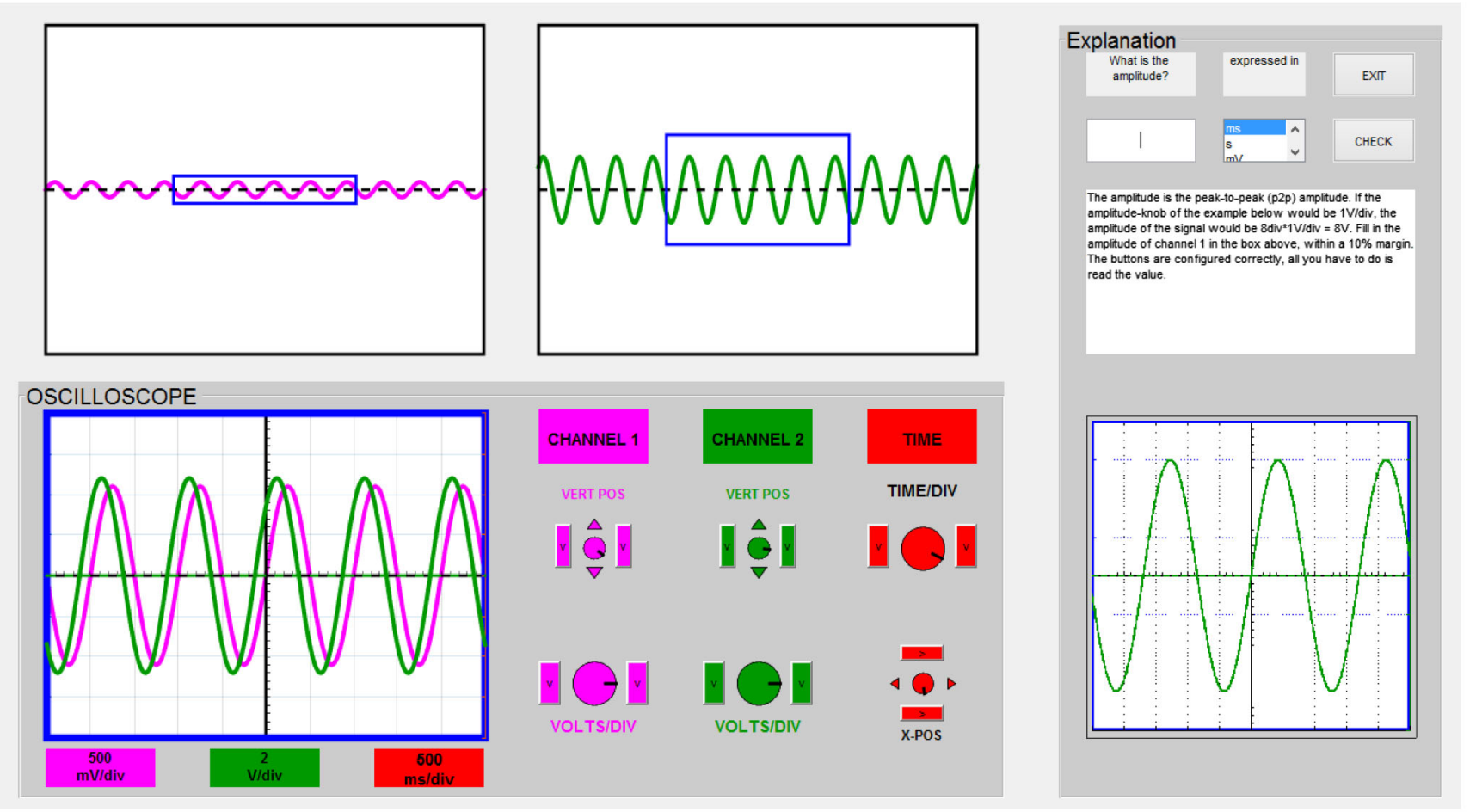

(c)

FIG. 8. Final version of the simulator. (a) In the first screen, the student can choose to practice reading a parameter at various levels of difficulty [well-configured oscilloscope, one setting (amplitude or time) misconfigured or fully misconfigured (both amplitude and time) scope] or to show the test to hand in at the beginning of the lab. (c) In the practice scope, there is an explanation about how to measure a parameter. The student can subsequently fill in the measurement value and choose the unit, after which the simulator will say whether it was correct or not. The test (b) now only shows the oscilloscope screen with two signals that the student has to measure. The measurements are to be handed in at the beginning of the lab. 
reading the frequency, amplitude, or phase of random signals with various levels of difficulty. In a first step, labeled "read" in Fig. 8(a), the buttons of the oscilloscope are properly configured, so the student only has to read the signal parameter. The simulator would then indicate whether or not the answer was correct. In a a next step, one set of buttons [time $(x)$ or amplitude $(y)$ ] is off in both the zoom and the position. This means that the student first has to adjust one set of buttons before being able to read the signal properly. In a final step, both sets of buttons are off, requiring the student to adjust both simultaneously before being able to read the parameters properly. In addition, a pane was added with an explanation on how to read each parameter. Whenever the students felt they were ready, they could then take the "test." As shown in Fig. 8(b), this test only showed an "oscilloscope" screen and its buttons. The

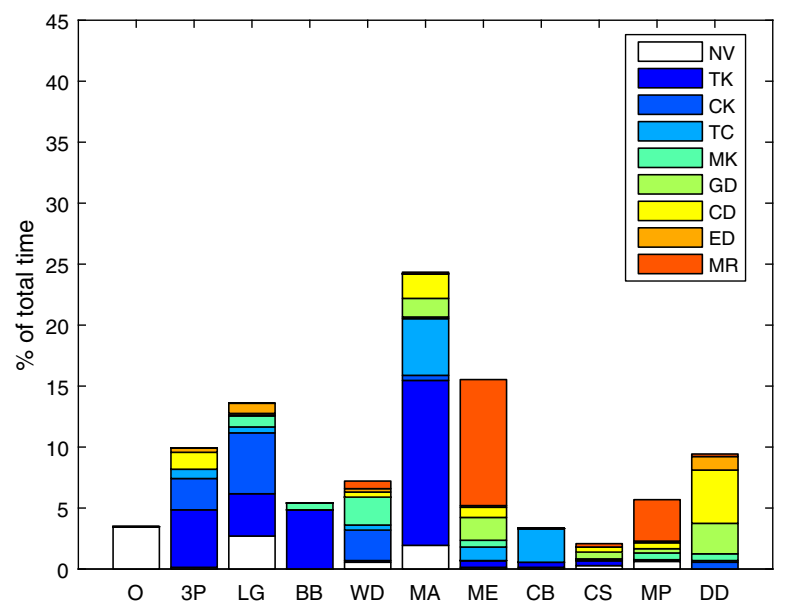

(a) Contexts for students at campus 1 with verbalization color-coded

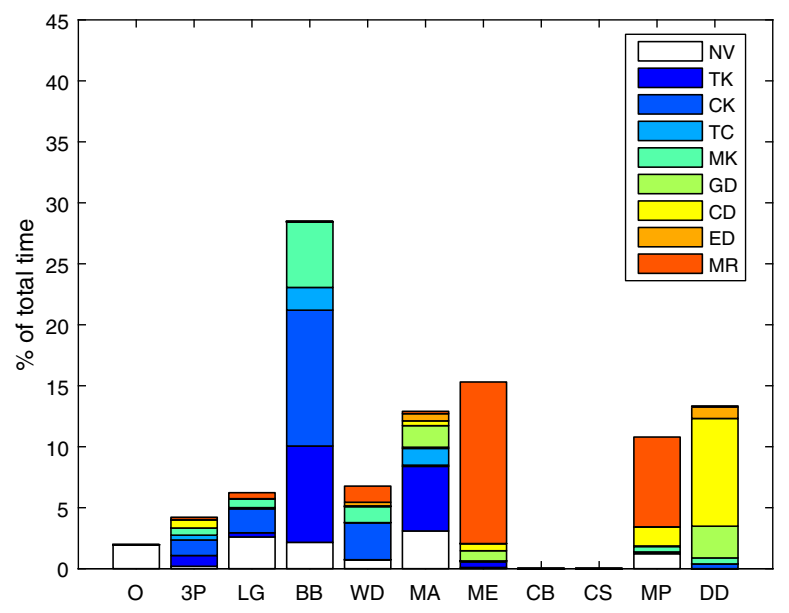

(c) Contexts for students at campus 2 with verbalization color-coded student then had to read all parameters, fill them in on their preparation sheet, and hand it in at the beginning of the laboratory.

The lab session itself was altered in the sense that instead of asking the students to measure the circuit with the switch in both positions, they only had to measure one. They would then get a Bode plot of the second circuit and were asked to determine what change the switch caused in their circuit based on their own measurements and the given Bode plot. The "ideal reasoning" here is similar to that of the pilot laboratory. In order to find out what the switch does, the students have to compare their measured cutoff frequency with the one of the Bode plot, which should be either half or double their measured one. Then, they have to measure the resistor value. If it has changed, the effect of the switch is clear: either a resistor was added in parallel

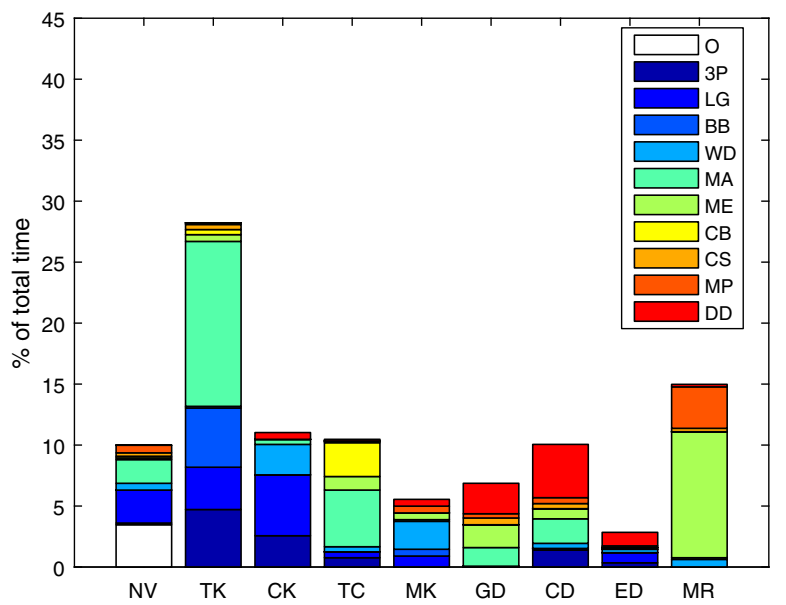

(b) Verbalizations for students at campus 1 with context color-coded

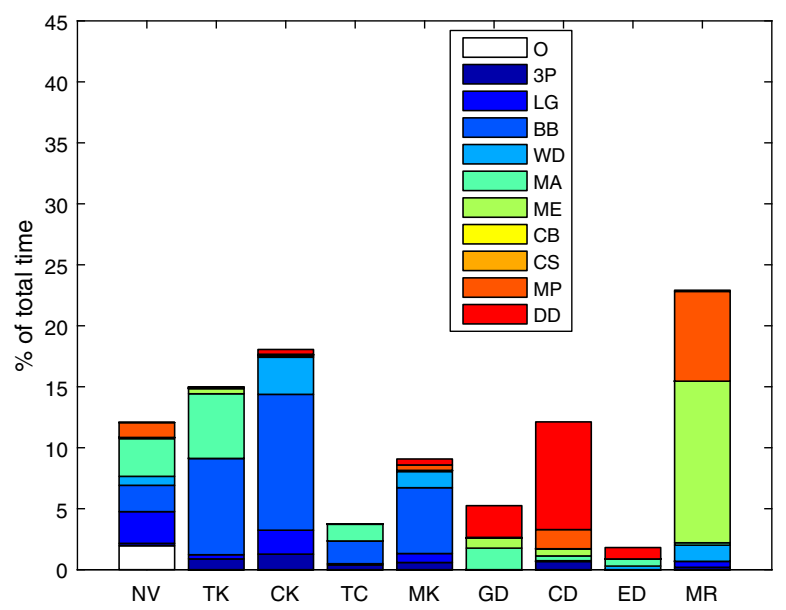

(d) Verbalizations for students at campus 2 with context color-coded

FIG. 9. Results of final labs. All percentages are the total of all pairs at the different campuses. Left are contexts with verbalization marked by colors (a) and (c), while right are verbalizations with the contexts marked by colors (b) and (d). The rows are campus 1 [(a) and (b)] and campus 3 [(c) and (d)], respectively. 
(lower $R$, but higher $f_{c}$ ) or series (higher $R$, lower $f_{c}$ ). If it is the same, a capacitor was added in series (halving $C$ but doubling $f_{c}$ ) or parallel (doubling $C$ and halving $f_{c}$ ). This adjustment was done for practical reasons at campus 3 , where the students only had $90 \mathrm{~min}$ to complete the lab. The students at this campus also did not have to write a report, so they were asked to hand in their measurements and both circuit diagrams at the end of the lab. At campus 1, similar changes were made, including adding the Bode plot of the second circuit and asking the students to hand in some measurement results at the end of the lab. Giving the students the Bode plot of the second circuit was also meant to reduce the time spent measuring, giving them more time for discussion. Asking the students to hand in their measurements and conclusions (circuits) at the end of the lab forced them to also process their measurements and to think about them during the lab session itself. At campus 1, the P. C. served as TA for the lab and reduced the time spent on the introduction.

\section{B. Results}

The results of this lab are shown in Fig. 9. The introduction by the TA was shorter than in the original lab. At campus 1, the P. C. taught the lab, shortening the introduction. At campus 3, the same teachers who taught the original laboratories gave the same introduction, but the change in the laboratory caused them to keep the introduction shorter as well. There was more time used by the students at campus 3 to perform more measurements (context ME) as well as to process them (context MP). They then also analyzed the measurements (context DD) and discussed them from a content-based point of view (verbalization $\mathrm{CD}$ ). At campus 1, the students spent less time performing measurements (context ME) than in the first version of the new lab. At this campus, more time was spent on three things. The first of these was the computer simulations: half of the students made their computer models (context $\mathrm{CB}$ ) in the lab instead of postponing it to after the lab. Second, they spent more time setting up their equipment (context MA). Finally, the students also discussed their measurements (context DD) a lot more during the lab, mostly from a content-based point of view (verbalization $\mathrm{CD}$ ).

\section{Discussion}

The preparation helped to speed up both the measurement process and the data processing (Bode plot). Reducing the number of required measurements by giving the Bode plot of the second circuit also helped to reduce the time spent measuring. The time the students had at their disposal was further increased by reducing the introduction of the TA. This extra time was spent on discussing the results of their measurements and the exact circuit configuration as well as building a computer model (at campus 1).

We found it surprising that the (prepared) students at campus 3 spent more time with their equipment (context MA), which was not seen in the pilot version of the black box laboratory. Reviewing the relevant sections of the video recordings showed this was due to one of the added qualitative conceptual questions which asked what the ac setting on an oscilloscope did. The students would then try this out on the oscilloscope while discussing this question, resulting in an increased amount of time spent manipulating equipment (context MA).

\section{CONCLUSION}

As a conclusion, we would like to evaluate both the methodology used (video observation) as well as the idea of using a black box teaching approach in a laboratory environment. Finally, some suggestions for future research are given.

\section{A. Video analysis}

The methodology used here allows us to gain insight in student activities as well as verbalizations during laboratories. The dual analysis of both what students are doing and what they are saying makes it a good tool to assess the interaction between student activities and speech, which is an expression of their thoughts. It made it possible to not only assess a laboratory session from this point of view, but also to modify it and to verify the changes made in a structured and consistent way. The methodology ensured it was possible to compare both laboratories in a richer way than a pretest post-test design allows by showing what students spend their time on and what activities are most likely to trigger useful interaction. This information provides useful insights to design specific lab activities and evaluate the "effectiveness 1" of those activities.

The methodology itself could be further refined by using a smaller time interval or by using a flexible time interval. This would eliminate having to choose between two things that happen more or less simultaneously. Also, despite the near-real-time encoding of the data, it is still very time consuming and is therefore not suitable for a big quantitative study without significant resources. Any results obtained using this approach remain qualitative in nature, but provide nevertheless a valuable framework to compare different laboratories. As such, it can be used to analyze and modify other laboratories, not limited to electronics, or even other teaching approaches.

The video data themselves could also be analyzed focusing on other aspects, e.g., by looking at metacognitive statements made by students [42-44] or to study certain episodes in more depth to verify what specific problems 
students have with various aspects of the lab (measuring phase shift seems to be nontrivial, for example).

\section{B. Black box lab}

The black box approach seems to motivate the students to find out what is in the box, as could be observed during the videos, as well as by informal conversation with the teaching assistants and the students themselves. Motivation is an important condition for learning in constructivist learning theory. However, there are also more concrete indications that this approach helps students to learn conceptually from a laboratory session.

One of the main issues raised in several studies was that students often follow instructions as if the manual is a cookbook [30] and do not evaluate or discuss their measurements critically during the lab [5,30,31]. Especially the latter is important, since it is a missing link [5] to achieve one of the main aims of laboratory instruction in engineering: to integrate theory and practice [20,21]. A related issue raised by Niedderer et al. [5] was that students generally spend too much time performing measurements. This was also clearly observed in the original laboratories and was related to the students' unfamiliarity with the measurement equipment (at least at campuses 1 and 3).

This greatly improved in the reformed labs by giving the students the chance to prepare with a simulator. The time spent on simply gathering measurements was further reduced by giving the students the Bode plot of the second circuit. This in turn gave them an opportunity to explicitly link their results back to their content knowledge, which was also indicated by our observation of the increase in data discussion (context DD) after this change was made. The use of the black box forced the students to decide the next frequency to measure by explicitly thinking about and discussing the previous measurement(s). This in turn required at least rough processing and analysis of those previous measurements. The students in the black box lab discussed their measurements with each other more often, not only after gathering all of them but also during the measurement process itself. We believe this to be at least partially thanks to the preparation, where students could practice measurement processing on a set of dummy measurements. In general, the black box laboratory increased the students' communication about content knowledge.

One aspect the students did not spend as much attention on in the new lab as in the original one was the phase shift between the input and output signals, despite having to do this in the preparation. A suggestion for future improvement is to require the students to determine the type of filter from one measurement alone (around the cutoff frequency), forcing them to use the phase and accurately measure its sign.

\section{Suggestions for future research}

The black box approach of the lab itself seems promising as an approach to force students to critically evaluate their measurements already during a laboratory session and could be extended to other labs, not limited to electronics. The idea of using reverse engineering in education is not new, but it is more used to teach engineering design methods rather than to teach content knowledge [45,46]. It is hoped that this study will stimulate further investigations in this field.

The idea of encoding both students' activities and verbalizations during lab work by using video recording is a very valuable tool in order to verify what activities trigger what kind of verbalization (and, consequently, thinking). However, there is no way to verify the "effectiveness 2" of the laboratory using this method, so combining the approach used here with another tool to evaluate the learning outcome could greatly increase understanding of student learning. This would also allow us to verify the claim made by Niedderer et al. that the verbalized knowledge during the laboratory is "an indicator for intended activities and learning" [5,32].

\section{ACKNOWLEDGMENTS}

The authors would very much like to thank all students who agreed to be videotaped during the laboratories, as well as their TA's for allowing us in their labs, also for their feedback and advice on the black box idea. Additionally, we are very grateful to our colleagues Laurens Bollen and Stijn Ceuppens for videotaping some of the lab sessions. We are also very grateful to Johan Willems for his help with the technical aspect of video and audio recording, as well as the postprocessing of the tapes. The help of Patrick Baumans and his colleagues was invaluable to make the boxes themselves, which we are, of course, very grateful for. A final word of thanks for Christian Kautz, who thoroughly read the manuscript of this paper and gave very valuable suggestions for improvement. 


\section{APPENDIX}

TABLE V. Categories for contexts.

\begin{tabular}{|c|c|c|c|c|c|}
\hline Code & Name & Explanation & Example & $\mathrm{CBAV}^{\mathrm{a}}$ & Warren $^{\mathrm{b}}$ \\
\hline $\mathrm{O}$ & Other & Things unrelated to the lab & Chat about last night's party & $\mathrm{O}$ & Off \\
\hline $3 \mathrm{P}$ & Third person & Third person intervenes in the group & The TA comes to answer a question & $3 \mathrm{P}$ & TA \\
\hline LG & Labguide & Use the labguide & Check the labguide to verify the set-up & LG & (TA) \\
\hline $\mathrm{BB}$ & Blackboard & Explanation to the whole class & The TA introduces the lab & LG & TA \\
\hline WD & Write \& discuss & Write and/or discuss & Prepare tables for a measurement & PP & $\mathrm{W}$ \\
\hline MA & Manipulate apparatus & Use the lab equipment & Build the circuit & MA & $\mathrm{P}$ \\
\hline ME & Measurement & Perform a (routine) measurement & Read the amplitude and write it down & $\mathrm{ME}$ & $\mathrm{P}$ \\
\hline $\mathrm{CB}$ & Build Computer model & Construct a simulation model & Make the first SPICE file & $\mathrm{CMB}$ & SMD \\
\hline CS & Computer simulation & Run a computer simulation & Run the ac simulation in multisim & CMU & $\mathrm{P}$ \\
\hline MP & Process measurement & Routinely process measurements & Convert the gain to $\mathrm{dB}$ & $\mathrm{CL}$ & $\mathrm{P}$ \\
\hline DD & Data discussion & Discuss their measurements & Argue about next measurement point & / & SM \\
\hline
\end{tabular}

${ }^{\mathrm{a}}$ As in Niedderer et al. [6].

${ }^{\mathrm{b}}$ As in Warren [24].

TABLE VI. Categories for verbalization.

\begin{tabular}{|c|c|c|c|c|c|}
\hline Code & Name & Explanation & Example & $\mathrm{CBAV}^{\mathrm{a}}$ & Warren $^{\mathrm{b}}$ \\
\hline TK & Technical knowledge & Knowledge related to equipment & Try to find the right button & KT & $\mathrm{P}(?)$ \\
\hline CK & Content knowledge & Knowledge about the content matter & Argue whether it is a LPF or HPF & KP & SM \\
\hline $\mathrm{TC}$ & Technical \& content & Technical and content intertwined & Why connect oscilloscope in parallel & $\mathrm{KTP}, \mathrm{KTP}_{i}$ & $\mathrm{SM}$ \\
\hline MK & Mathematical knowledge & State a mathematical formula & State the formula for $f_{c}$ & KM & SMM \\
\hline GD & Geometrical description & Describe data geometrically & "The output voltage increases" & KMM & $\mathrm{SM}(\mathrm{U})$ \\
\hline $\mathrm{CD}$ & Content-based description & Content-based data interpretation & "This is $f_{c}$, the phase is $45^{\circ}$ " & KMP/KMT & $\mathrm{SM}(\mathrm{A})$ \\
\hline ED & Example-based description & Compare data to an example & "The graph looks like in the manual" & / & I \\
\hline MR & Measurement reading & Read the value of a measurement & "Now the amplitude is $5 \mathrm{~V} "$ & / & $\mathrm{P}$ \\
\hline NV & No verbalization & No, unclear or irrelevant talk & Discuss last night's party & / & / \\
\hline
\end{tabular}

${ }^{\mathrm{a}}$ As in Niedderer et al. [6].

${ }^{\mathrm{b}}$ As in Warren [24].

[1] P. Coppens, J. Van den Bossche, and M. De Cock, Goals of lab work in electronics: Student and staff ideas, Int. J. Electr. Eng. Educ. 53, 124 (2015).

[2] C. Wieman and N. G. Holmes, Measuring the impact of an instructional laboratory on the learning of introductory physics, Am. J. Phys. 83, 972 (2015).

[3] H. E. P. Tattje and H. Vos, Improvement of a laboratory course in network analysis-learning to validate knowledge in an experimental way, IEEE Trans. Ed. 38, 17 (1995).

[4] P. Coppens, M. De Cock, and C. H. Kautz, Student Understanding of Filters in Analog Electronics Lab Courses, in Proceedings of the 40th SEFI Annual Conference: Engineering Education 2020: Meet the Future, edited by A. Avdelas (SEFI, Thessaloniki, 2012), pp. 196-197.
[5] H. Niedderer, A. Tiberghien, C. Buty, K. Haller, L. Hucke, F. Sander, H. Fischer, H. Schecker, S. Aufschnaiter, and M. Welzel, Category Based Analysis of Videotapes from Labwork (CBAV) - Method and Results from Four CaseStudies, Technical Report of The European Commission, Targeted Socio-Economic Research Programme; Project PL 95-2005: Labwork in Science Education, 1998.

[6] L.S. Vygotski, Mind in Society: The Development of Higher Psychological Processes, edited by M. Cole (Harvard University Press, Cambridge, 1978), p. 151.

[7] D. C. Phillips, The good, the bad, and the ugly: The many faces of constructivism, Educ. Res. 24, 5 (1995).

[8] M. T. H. Chi, Three types of conceptual change: Belief revision, mental model transformation, and categorical shift, in Handbook of Research on Conceptual Change, 
edited by Stella Vosniadou (Routledge, New York, 2008), Chap. 3, pp. 61-82.

[9] M. T.H. Chi, Commonsense conceptions of emergent processes: Why some misconceptions are robust, J. Learn. Sci. 14, 161 (2005).

[10] J. P. Smith III, A. A. DiSessa, and J. Roschelle, Misconceptions reconceived: A constructivist analysis of knowledge in transition, J. Learn. Sci. 3, 115 (1994).

[11] R. S. Nickerson, Confirmation bias: A ubiquitous phenomenon in many guises, Rev. Gen. Psychol. 2, 175 (1998).

[12] J. Sweller, J. J. G. van Merrienboer, and F. G. W. C. Paas, Cognitive architecture and instructional design, Educ. Psychol. Rev. 10, 251 (1998).

[13] A. Tiberghien, L. Veillard, J.-F. Le Marechal, C. Buty, and R. Millar, An analysis of labwork tasks used in science teaching at upper secondary school and university levels in several European countries, Sci. Educ. 85, 483 (2000).

[14] L. D. Feisel and A. J. Rosa, The role of the laboratory in undergraduate engineering education, J. Eng. Educ. 94, 121 (2005).

[15] J. W. Wilkinson and M. Ward, The purpose and perceived effectiveness of laboratory work in secondary schools, Aust. Sci. Teachers J. 43, 49 (1997).

[16] A. Berry, R. Gunstone, P. Mulhall, and J. Loughran, Helping students learn from laboratory work, Aust. Sci. Teachers J. 45, 27 (1999).

[17] C. Hart, P. Mulhall, A. Berry, J. Loughran, and R. Gunstone, What is the purpose of this experiment? Or can students learn something from doing experiments?, J. Res. Sci. Teach. 37, 655 (2000).

[18] A. Hofstein and V. N. Lunetta, The role of the laboratory in science teaching: Neglected aspects of research, Rev. Educ. Res. 52, 201 (1982).

[19] D. Hodson, Research on practical work in school and universities: In pursuit of better questions and better method, in Proceedings of the 6th European Conference on Research in Chemical Education, Aveiro, 2001.

[20] N. S. Edward, The role of laboratory work in engineering education: Student and staff perceptions, Int. J. Electr. Eng. Educ. 39, 11 (2002).

[21] J. Blue and J. Jacob, Student perceptions of an introductory laboratory course, AIP Conf. Proc. 1179, 101 (2009).

[22] M.-G. Séré, J. Leach, H. Niedderer, D. Psillos, A. Tiberghien, and M. Vicentini, Improving Science Education: Issues and Research on Innovative Empirical and Computer-Based Approaches to Labwork in Europe, Tech. Rep. (1998).

[23] A. R. Warren, Network analysis of social interactions in laboratories, AIP Conf. Proc. 1064, 219 (2008).

[24] J. B. Stang and I. Roll, Interactions between teaching assistants and students boost engagement in physics labs, Phys. Rev. ST Phys. Educ. Res. 10, 020117 (2014).

[25] F. Depaepe, E. De Corte, and L. Verschaffel, Unraveling the culture of the mathematics classroom: A video-based study in sixth grade, Int. J. Educ. Res. 46, 266 (2007).

[26] R. E. Scherr, Video analysis for insight and coding: Examples from tutorials in introductory physics, Phys. Rev. ST Phys. Educ. Res. 5, 020106 (2009).

[27] C. Von Aufschnaiter, Interactive processes between university students: Structures of interactions and related cognitive development, Res. Sci. Educ. 33, 341 (2003).
[28] A. Karelina and E. Etkina, When and how do students engage in sense-making in a Physics Lab?, AIP Conf. Proc. 883, 93 (2007).

[29] C. Von Aufschnaiter and S. Von Aufschnaiter, University students' activities, thinking and learning during laboratory work, Eur. J. Phys. 28, S51 (2007).

[30] A. Hofstein and V. N. Lunetta, The laboratory in science education: Foundations for the twenty-first century, Sci. Educ. 88, 28 (2004).

[31] W.-m. Roth, C. J. Mcrobbie, K. B. Lucas, and S. Boutonné, Why may students fail to learn from demonstrations? A social practice perspective on learning in physics, J. Res. Sci. Teach. 34, 509 (1997).

[32] J. Bliss, Piaget und Vygotsky: Ihre Bedeutung für das Lehren und Lernen der Naturwissenschaften, Zeitschrift Für Didaktik Der Naturwissenschaften 2, 3 (1996).

[33] J. Cohen, A coefficient of agreement for nominal scales, Educ. Psychol. Meas. 20, 37 (1960).

[34] J. R. Landis and G. G. Koch, The measurement of observer agreement for categorical data, Biometrics 33, 159 (1977).

[35] J. Bernhard, A tool to see with or just something to manipulate? Investigating engineering students' use of oscilloscopes in the laboratory, in Proceedings of the Société Européenne pour la Formation des Ingénieurs Annual Conference (SEFI), Orléans, 2015 (SEFI, Orléans, 2015), ftp://ftp.rz.uni-kiel.de/ pub/ipn/zfdn/1996/Heft3/S.3-16_Bliss_96_H3.pdf.

[36] C. Terry, Black-Box Electrical Circuits, Phys. Teach. 33, 386 (1995).

[37] C. Keller and Y. Wang, A Golden Oldie-A Black Box Circuit, Phys. Teach. 32, 222 (1994).

[38] M. E. Holder, Thevenin's theorem and a black box, IEEE Trans. Ed. 52, 573 (2009).

[39] J. Bernhard, Insightful learning in the laboratory: Some experiences from 10 years of designing and using conceptual labs, Eur. J. Eng. Educ. 35, 271 (2010).

[40] P. S. Shaffer and L. C. McDermott, Research as a guide for curriculum development: An example from introductory electricity. Part II: Design of instructional strategies, Am. J. Phys. 60, 1003 (1992).

[41] L. C. McDermott, How we teach and how students learn-A mismatch?, Am. J. Phys. 61, 295 (1993).

[42] R. Lippmann, Analyzing students use of metacognition during laboratory activities, in American Educational Research Association (AERA) Annual Conference: Validity and Value in Education Research (AERA, New Orleans, LA, 2002), pp. 1-9, http://www.physics.umd.edu/perg/ papers/lippmann/meta_lab.pdf.

[43] R. L. Kung and C. Linder, Metacognitive activity in the physics student laboratory: Is increased metacognition necessarily better?, Metacognit. Learn. 2, 41 (2007).

[44] E. C. Sayre and P. W. Irving, Brief, embedded, spontaneous metacognitive talk indicates thinking like a physicist, arXiv:1409.7590.

[45] K. L. Wood, D. Jensen, J. Bezdek, and K. N. Otto, Reverse engineering and redesign: Courses to incrementally and systematically teach design, J. Eng. Educ. 90, 363 (2001).

[46] R. E. Barr, P. S. Schmidt, T. J. Krueger, C.-Y. Twu, and Advanced Micro Devices, An introduction to engineering through an integrated reverse engineering and design graphics project, J. Eng. Educ. 89, 413 (2000). 